\title{
Glial Cell Line-Derived Neurotrophic Factor Gene Delivery in Parkinson's Disease: A Delicate Balance between Neuroprotection, Trophic Effects, and Unwanted Compensatory Mechanisms
}

\author{
Liliane Tenenbaum * and Marie Humbert-Claude \\ Laboratory of Cellular and Molecular Neurotherapies, Clinical Neuroscience Department, Center for Neuroscience Research, \\ Lausanne University Hospital, Lausanne, Switzerland
}

OPEN ACCESS

Edited by:

Jose L. Lanciego,

Universidad de Navarra, Spain

Reviewed by:

Kazuto Kobayashi,

Fukushima Medical University, Japan

Bernard Laurent Schneider,

École Polytechnique Fédérale de

Lausanne, Switzerland

*Correspondence:

Liliane Tenenbaum

liliane.tenenbaum@chuv.ch

Received: 27 October 2016 Accepted: 23 March 2017

Published: 10 April 2017

Citation:

Tenenbaum $L$ and Humbert-Claude $M$ (2017) Glial Cell Line-Derived Neurotrophic Factor Gene Delivery in

Parkinson's Disease: A Delicate Balance between Neuroprotection,

Trophic Effects, and Unwanted

Compensatory Mechanisms.

Front. Neuroanat. 11:29.

doi: 10.3389/fnana.2017.00029
Glial cell line-derived neurotrophic factor (GDNF) and Neurturin (NRTN) bind to a receptor complex consisting of a member of the GDNF family receptor (GFR)- $\alpha$ and the Ret tyrosine kinase. Both factors were shown to protect nigro-striatal dopaminergic neurons and reduce motor symptoms when applied terminally in toxin-induced Parkinson's disease (PD) models. However, clinical trials based on intraputaminal GDNF protein administration or recombinant adeno-associated virus (rAAV)-mediated NRTN gene delivery have been disappointing. In this review, several factors that could have limited the clinical benefits are discussed. Retrograde transport of GDNF/NRTN to the dopaminergic neurons soma is thought to be necessary for NRTN/GFR- $\alpha /$ Ret signaling mediating the pro-survival effect. Therefore, the feasibility of treating advanced patients with neurotrophic factors is questioned by recent data showing that: (i) tyrosine hydroxylase-positive putaminal innervation has almost completely disappeared at 5 years post-diagnosis and (ii) in patients enrolled in the rAAV-NRTN trial more than 5 years post-diagnosis, NRTN was almost not transported to the substantia nigra pars compacta. In addition to its anti-apoptotic and neurotrophic properties, GDNF also interferes with dopamine homeostasis via time and dose-dependent effects such as: stimulation of dopamine neuron excitability, inhibition of dopamine transporter activity, tyrosine hydroxylase phosphorylation, and inhibition of tyrosine hydroxylase transcription. Depending on the delivery parameters, the net result of this intricate network of regulations could be either beneficial or deleterious. In conclusion, further unraveling of the mechanism of action of GDNF gene delivery in relevant animal models is still needed to optimize the clinical benefits of this new therapeutic approach. Recent developments in the design of regulated viral vectors will allow to finely adjust the GDNF dose and period of administration. Finally, new clinical studies in less advanced patients are warranted to evaluate the potential of AAV-mediated neurotrophic factors gene delivery in PD. These will be facilitated by the demonstration of the safety of rAAV administration into the human brain.

Keywords: GDNF, RET, tyrosine hydroxylase, dopamine transporter, retrograde signaling, neurturin, AAV 


\section{GLIAL CELL LINE-DERIVED NEUROTROPHIC FACTOR GENE DELIVERY: PRECLINICAL FINDINGS IN ANIMAL MODELS}

Glial cell line-derived neurotrophic factor (GDNF) has first been shown to protect embryonic dopaminergic neurons in vitro (Lin et al., 1993). GDNF and related factors, such as neurturin (NRTN), signal through a multicomponent receptor system consisting of a glycosyl-phosphatidylinositol-anchored receptor, the GDNF family receptor (GFR)- $\alpha$ and Ret tyrosine kinase (Paratcha and Ledda, 2008). GDNF and NRTN preferentially bind to GFR- $\alpha 1$ and GFR- $\alpha 2$, respectively (Sariola and Saarma, 2003). In the absence of Ret, GDNF in complex with GFR- $\alpha 1$ may also interact with heparan sulfate glycosaminoglycans to activate the c-Met receptor tyrosine kinase and to neural cell adhesion molecule (NCAM) which activates the Src-like kinase Fyn and focal adhesion kinase (FAK; Sariola and Saarma, 2003).

Since dopaminergic neurons express both GFR $\alpha$ and Ret in the rodent (Jing et al., 1997; Walker et al., 1998) and human (Walker et al., 1998; Quartu et al., 2007) brain, it was soon hoped that GDNF could have a therapeutic potential for Parkinson's disease (PD) (Tomac et al., 1995). The therapeutic benefit of GDNF and NRTN has been demonstrated in phenotypic, toxin-induced [6-hydroxydopamine (6-OHDA) and 1-methyl4-phenyl-1,2,3,6-tetrahydropyridine (MPTP)] rodent and nonhuman primate models of PD (Bilang-Bleuel et al., 1997; ChoiLundberg et al., 1997; Mandel et al., 1999; Kirik et al., 2000; Kordower et al., 2000; Eslamboli et al., 2003, 2005; Kordower et al., 2006; Gasmi et al., 2007a,b; Ramaswamy et al., 2007; Herzog et al., 2008, 2009; Su et al., 2009). Ret induces the serine/threonine kinase AKT and extracellular signal-regulated kinase (ERK) signaling which mediate pro-survival and neurotrophic activities (Sariola and Saarma, 2003). In favor of this hypothesis, it was shown that the absence of Ret signaling caused progressive degeneration of the nigrostriatal system (Kramer et al., 2007). These data are however, in contradiction with another study suggesting that GDNF is dispensable for dopaminergic neurons survival (Kopra et al., 2015). Since GDNF does not pass the blood-brain barrier, intracerebral gene delivery by stereotaxic injection of viral vectors has been proposed as a method of administration. The therapeutic potential of GDNF gene delivery has been evaluated in different pre-clinical paradigms.

\section{Neuroprotection vs. Neurorestoration}

In the neuroprotective paradigm, a viral vector encoding GDNF is administered prior to lesioning the nigro-striatal dopaminergic pathway whereas in the neurorestorative paradigm, the vector is administered after lesioning. While a large number of neuroprotection studies (Bilang-Bleuel et al., 1997; ChoiLundberg et al., 1997; Mandel et al., 1999; Bensadoun et al., 2000; Kirik et al., 2000; Kordower et al., 2000; Eslamboli et al., 2005; Bartus et al., 2011) have been published, only few works aimed at evaluating a potential neurorestorative effect (Kozlowski et al., 2000; Yang et al., 2009; Tereshchenko et al., 2014). In addition, the latter paradigm can refer to different approaches. Indeed, GDNF administration has been performed either during the progressive phase (Kozlowski et al., 2000) or after stabilization of the lesion (Wang et al., 2002; Zheng et al., 2005; Eberling et al., 2009).

In both paradigms, increased numbers of SNpc dopaminergic neurons stained by antibodies directed against tyrosine hydroxylase (TH), an enzyme of the DA biosynthesis pathway, and attenuation of the motor symptoms have been demonstrated.

\section{Intranigral vs. Intrastriatal Delivery}

Two delivery sites were used and sometimes combined: the SN (Choi-Lundberg et al., 1997; Mandel et al., 1997; Bensadoun et al., 2000) and the striatum (Bilang-Bleuel et al., 1997; Connor et al., 1999; Kirik et al., 2000) in order to deliver GDNF respectively to the dopaminergic neurons cell soma and at the level of their terminals. In some instances, both approaches were combined (Kirik et al., 2000; Kordower et al., 2000).

Most of the studies performed in the neuroprotection paradigm indicated that when GDNF was administered at the level of the SN, cell bodies were protected but no benefit on motor symptoms was observed (Bilang-Bleuel et al., 1997; Mandel et al., 1999). In contrast, when GDNF was administered into the striatum, both cell bodies and terminals were preserved and motor symptoms were reduced (Kirik et al., 2000). Accordingly, several recent studies have suggested that axonal dysfunction precedes neuronal cell death and is better correlated with clinical symptoms (see further; Burke and O'Malley, 2013; Kordower et al., 2013; Schulz-Schaeffer, 2015).

In one report, the authors succeeded to obtain a protection after intranigral delivery of an adenoviral vector in the neurorestorative paradigm (Kozlowski et al., 2000). Strikingly, in this study, dopaminergic neurons survival was assessed by injecting a retrograde tracer, Fluorogold, into the striatum and counting the number of Fluorogold-positive neurons in the SNpc. By that mean, all neurons which still have nigro-striatal projections proficient for retrograde transport are taken into account. In contrast, in the same study, the number of cells expressing $\mathrm{TH}$ in the $\mathrm{SNpc}$ was not increased by the GDNF treatment. Other studies reported a lack of matching between TH staining and retrograde Fluorogold labeling of nigrostriatal neurons (Sauer and Oertel, 1994). The loss of the TH marker could indicate that the neurons were dysfunctional but still present and possibly rescuable. Thus, the method to assess neuronal survival and pathway integrity is crucial. Neuronal survival evaluation solely based on TH immunostainings could provide misleading interpretations.

\section{Perturbations of Dopamine Homeostasis by Excessive GDNF Overexpression}

DA is submitted to an intricate network of regulations controlling its homeostasis (see Figure 1). Firstly, DA regulates its own synthesis by binding to $\mathrm{TH}$ and retro-inhibiting its activity (Gordon et al., 2008). After release in the synaptic cleft, DA is rapidly re-uptaken by the dopamine transporter (DAT; Nirenberg et al., 1996; Uhl, 2003). Finally, binding to the presynaptic $\mathrm{D}_{2} \mathrm{R}$ autoreceptor results in a negative feed-back on DA synthesis and release (Westerink et al., 1994) whereas binding to 


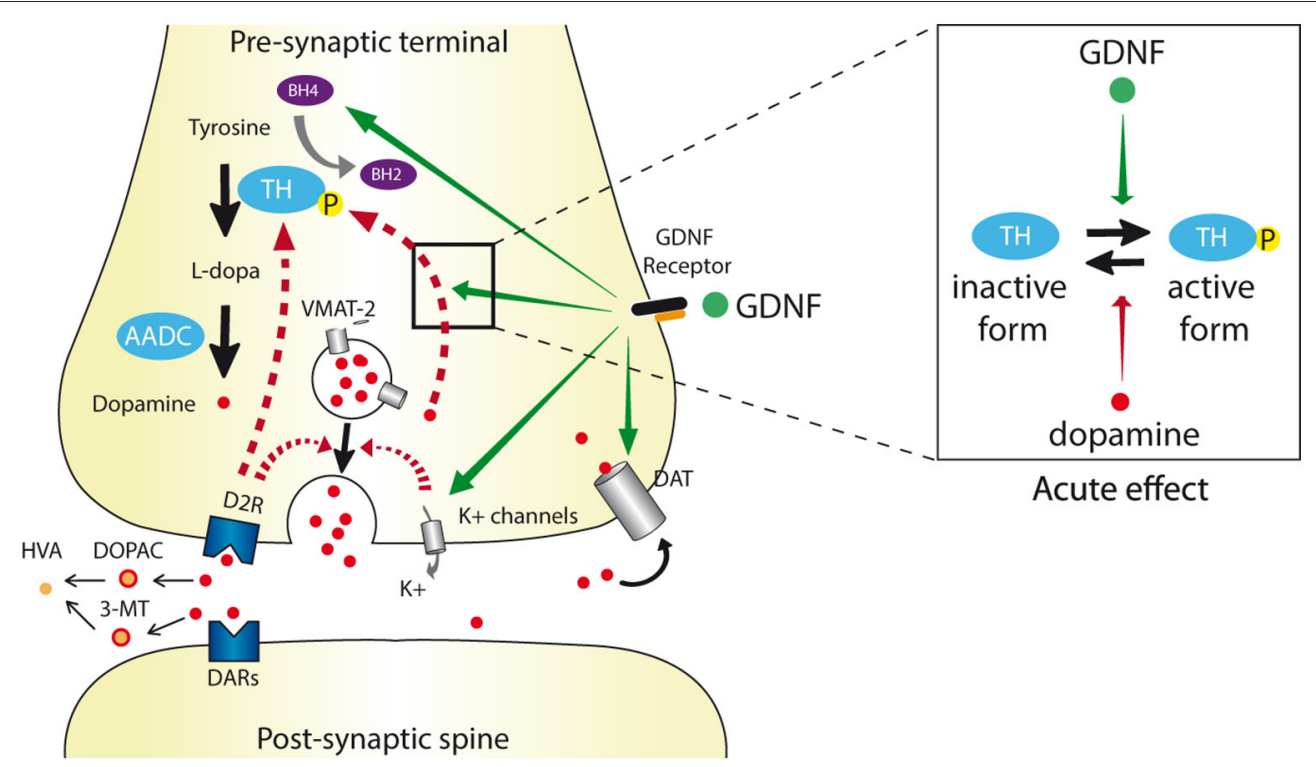

FIGURE 1 | Schematic dopaminergic synapse depicting the different levels of GDNF regulation. The dopamine synthesis, release, re-uptake, and degradation pathways are indicated by black arrows. Dopamine is synthesized by conversion of tyrosine to L-DOPA by tyrosine hydroxylase (TH) that uses tetrahydrobiopterin $(\mathrm{BH} 4)$ as a cofactor. L-DOPA is converted to dopamine by aromatic acid decarboxylase (AADC) and then integrated into pre-synaptic vesicles via the vesicular monoamine transporter 2 (VMAT2). After release into the synaptic cleft via exocytosis, dopamine acts on its receptors (DAR), is uptaken by the dopamine transporter (DAT) and degraded into 3-methoxytyramine (3-MT) and 3,4 dihydroxyphenyl acetic acid (DOPAC) leading to the final homovanillic acid (HVA) metabolite. Physiological negative feedback on dopamine release is indicated in hatched red arrows. GDNF alters dopaminergic transmission (orange arrows) by (i) increasing the BH4 levels, (ii) increasing $\mathrm{Ca}^{2+}$-evoked-dopamine release via inhibition of $\mathrm{K}+$ channels and subsequent membrane depolarization, and (iii) reducing DAT activity. Depending of the GDNF dose and administration period, the ratio of TH and phosphorylated (active) TH levels can be either increased or decreased. Except for DAT regulation, the direct or indirect impact of the GDNF receptor complex (RET/GFR $\alpha 1$ ) on these herein described levels of regulation still need to be clarified.

$\mathrm{D}_{1} \mathrm{R}$-type receptor on striatal medium spiny projection neurons provides a long-loop retro-control (Saklayen et al., 2004).

GDNF interferes with DA homeostasis at different levels (see Figure 1 and Table 1). It increases DA available in the synaptic cleft via different mechanisms such as: (i) stimulation of TH phosphorylation, which blocks the DA binding site and thus reduces the retro-inhibition of $\mathrm{TH}$ activity (Ramsey and Fitzpatrick, 1998; Gordon et al., 2008); (ii) GDNF enhancement of DA release via inhibition of a $\mathrm{A}$ type $\mathrm{K}^{+}$channel thus provoking depolarization and $\mathrm{Ca}^{2+}$ entry (Hebert et al., 1996; Bourque and Trudeau, 2000; Yang et al., 2001); (iii) reduction of DAT activity via Ret/DAT interaction (Airavaara et al., 2004; Boger et al., 2007; Littrell et al., 2012; Barroso-Chinea et al., 2016). These effects can ultimately lead to compensatory mechanisms such as downregulation of TH transcription (Georgievska et al., 2002a).

Consequently, important variations of GDNF level are likely to profoundly perturb DA homeostasis. Whether a "normal" dopaminergic neurotransmission can be restored in the presence of supraphysiological GDNF concentrations cannot be predicted. Not surprisingly, long-term uncontrolled and sustained GDNF overexpression has led to compensatory changes (Georgievska et al., 2002b; Barroso-Chinea et al., 2016) that could have outweighed trophic effects. In contrast, a moderate GDNF overexpression is likely to compensate a diminished neurotrophic environment (Chauhan et al., 2001) and provide the possibility to re-establish a physiological DA homeostasis (Kumar et al., 2015). Indeed, a 60\% increased GDNF level was sufficient to observe a protective effect toward a 6OHDA lesion. Similarly, in other studies, neuroprotective effects in the absence of $\mathrm{TH}$ downregulation have been obtained by applying low GDNF doses either by injecting a low amount of viral vector (Eslamboli et al., 2005) or by controlling the level of transgene expression (Barroso-Chinea et al., 2016; Chtarto et al., 2016). Interestingly, using a discontinuous GDNF delivery paradigm in the partial rat 6-OHDA model, also allowed to reduce the behavioral symptoms as well as to maintain VMAT2-positive cells and innervation in the absence of $\mathrm{TH}$ downregulation (Tereshchenko et al., 2014).

\section{Pro-Survival vs. Neurochemical Effects}

Given the above-described GDNF-mediated multiple effects on dopaminergic neurotransmission, the mechanism of the neuroprotective effects observed in the numerous gene delivery studies (Bilang-Bleuel et al., 1997; Choi-Lundberg et al., 1997; Mandel et al., 1999; Kirik et al., 2000; Kordower et al., 2000) can be questioned. Whether neurons were protected against pro-apoptotic pathways or whether surviving but dysfunctional neurons were boosted to re-express lost markers is still an open question.

In addition to "waking-up" dysfunctional dopaminergic neurons, stimulation of striatal reinnervation in remaining healthy neurons (without increase of the number of cell bodies) is also a potential mechanism (Brizard et al., 2006). In particular, 


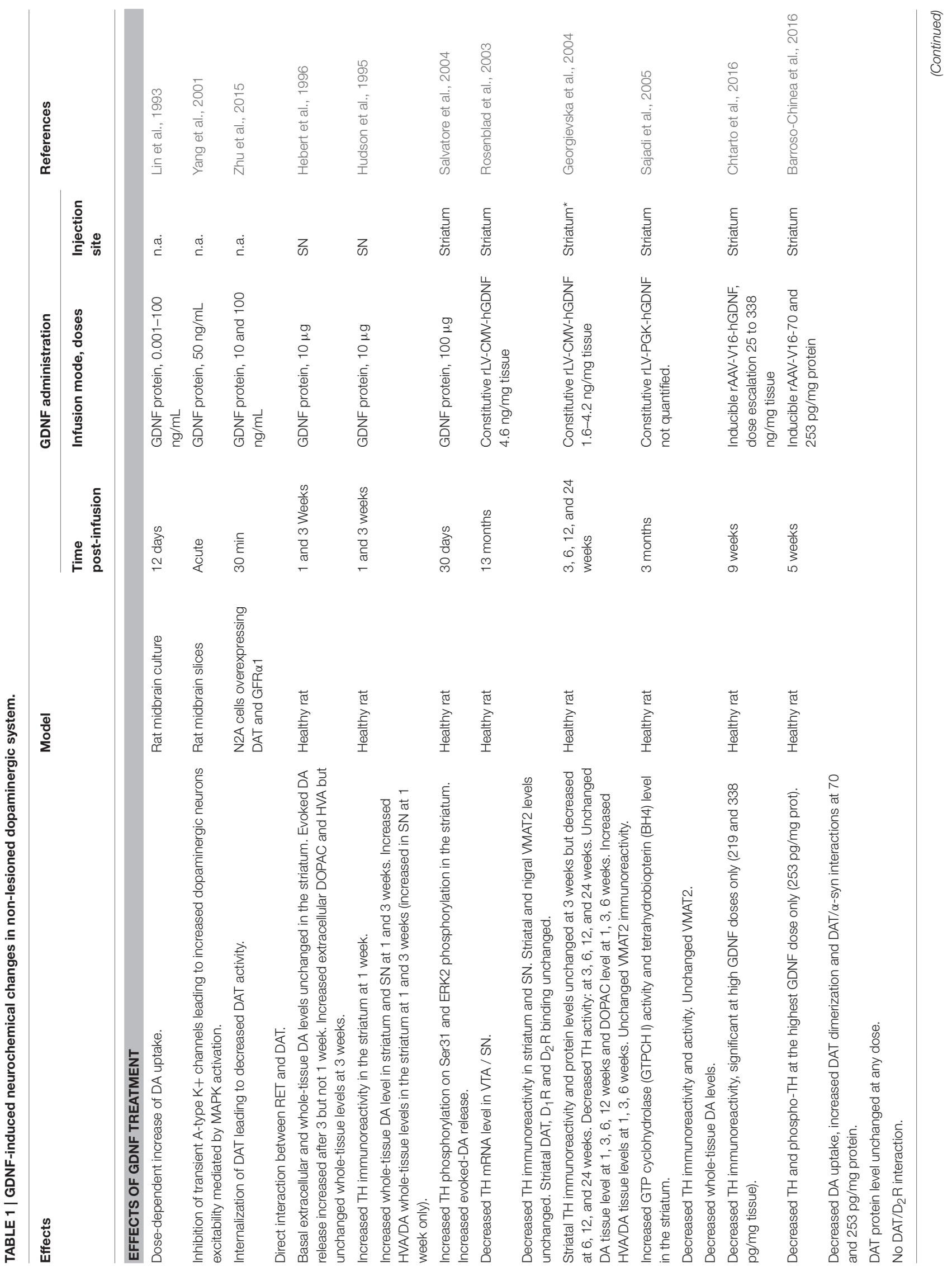




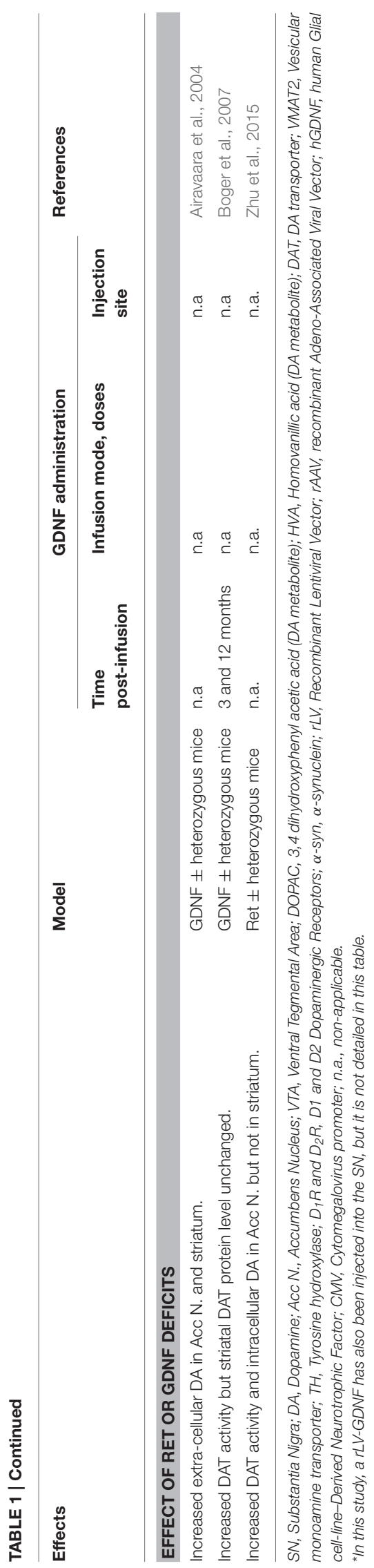

increased TH activity, through phosphorylation (Salvatore et al., 2004) and reduction of DAT activity (Barroso-Chinea et al., 2016) both leading to increased extracellular DA levels probably contribute, in addition to neuroprotection, to the observed behavioral benefits. In conclusion, several GDNF-mediated effects not related to its anti-apoptotic mechanism, could have biased the interpretation of behavioral and histological data (especially when TH alone was taken as a criteria; Sajadi et al., 2005; Yang et al., 2009; Barroso-Chinea et al., 2016).

\section{Cell Type Secreting GDNF}

In the striatum, endogenous GDNF is expressed by parvalbuminpositive interneurons (Hidalgo-Figueroa et al., 2012). The different classes of viral vectors used to deliver GDNF [adenoviral vector (Choi-Lundberg et al., 1997; Connor et al., 1999; Kozlowski et al., 2000); lentiviral vectors (Bensadoun et al., 2000); and recombinant adeno-associated virus (rAAV)-based vectors (Mandel et al., 1999; Kirik et al., 2000)] transduce different cell types with varying efficiencies. The promoter used for transgene expression further influences the cell type specificity (Bockstael et al., 2008). In most studies, this issue has not been evaluated. Some vectors transduce the more abundant medium spiny neurons which project to the globus pallidus and $\mathrm{SNr}$, thus resulting in an anterograde transport of the transgene product in these structures (Bockstael et al., 2008). In order to avoid this dissemination of GDNF in non-targeted structures which can provoke undesired effects (Manfredsson et al., 2009), some groups have directed GDNF expression into astrocytes in order to restrict transgene expression to the delivery site in the striatum (Do Thi et al., 2004; Pertusa et al., 2008; Drinkut et al., 2012). Considering the different cell type specificities of transgene expression mediated by the different vectors and the variable amounts of GDNF produced (see Table 1), it is very difficult to compare studies performed using different viral vectors.

Interestingly, mice which were manipulated to overexpress GDNF from the native locus (by deletion of miR-binding sites in the $3^{\prime}$ untranslated region) had an increased number of dopaminergic cells in the substantia nigra pars compacta (SNpc) as well as increased dopaminergic innervation and dopamine (DA) release in the striatum (Kumar et al., 2015). However, when these mice were treated with 6-OHDA, an aggravation of the DA level decrease in the striatum and dopaminergic neurons loss was observed. This surprising result was attributed to GDNF-mediated stimulation of DAT activity which increases 6-OHDA uptake. In order to evaluate GDNF neuroprotective effect using a toxin which does not depend on DAT, the authors injected lactacystin, a proteasome inhibitor which induces alphasynuclein accumulation in nigral neurons. Although, motor symptoms were improved and dopaminergic levels were higher in GDNF hypermorphic mice the mutant mice, the number of dopaminergic neurons was not increased. As already outlined in Section Pro-Survival vs. Neurochemical Effects, this recent study further suggests that, due to the pleiotropy of GDNF functions, confounding factors might have biased the interpretation of putative pro-survival effects in previous studies. 


\section{NEUROTROPHIC FACTORS GENE DELIVERY: STILL A PROMISING CLINICAL PARADIGM FOR PARKINSON'S DISEASE?}

Clinical trials were conducted using catheters releasing recombinant GDNF protein (Nutt et al., 2003; Lang et al., 2006) as well as rAAV serotype 2 (rAAV2)-mediated delivery of the NRTN (Marks et al., 2010; Warren Olanow et al., 2015) or GDNF cDNA (https://clinicaltrials.gov/ct2/show/NCT01621581?term= AAV2-GDNF\&rank=1). In the Phase I trials, AAV vectors were safe. However, the Phase II results were disappointing, although beneficial effects have been described for patients which have been followed for longer periods (Marks et al., 2010). Several factors could have reduced clinical benefits.

\section{Impact of Axonopathy on NRTN Signaling}

The patients were enrolled in the AAV2-NRTN clinical trial at very late stages of the disease, usually more than 5 years post-diagnosis (Marks et al., 2010). Analysis of brains from untreated PD patients at different stages, from 1 to 37 years postdiagnosis, showed that the putaminal innervation, as measured by immunostaining against $\mathrm{TH}$, had almost totally disappeared from 4 years post-diagnosis (Kordower et al., 2013). In contrast, numerous TH-positive dopaminergic neurons were still present in the SNpc. These data are in accordance with other studies pointing to a dying-back degeneration of dopaminergic neurons in PD. The current view that more than $80 \%$ dopaminergic neurons have died at the time of diagnosis has been revisited using new techniques to evaluate the number of surviving neurons and the putaminal dopaminergic innervation (using radioactive ligand binding to DAT; Burke and O'Malley, 2013; Kurowska et al., 2016). These data demonstrate that the extent of neuronal death at the time of symptoms onset is only $30 \%$ whereas putaminal DA levels were $50-70 \%$ reduced, suggesting that axon terminals become dysfunctional prior to cell death.

Post-mortem analysis of four patients enrolled in the AAV2NRTN trial, showed that although surviving melanin-positive dopaminergic neurons were still present in the SNpc, THpositive dopaminergic terminals in the putamen were very sparse and NRTN transport from the putamen to the SNpc was very slow and inefficient (Bartus et al., 2011, 2015). It should be noted that this analysis was based uniquely on TH immunohistochemistry. Thus, it cannot be excluded that dopaminergic projections were still present but did not express TH. Indeed, as already discussed above, TH expression does not always correlate with other dopaminergic markers, such as the vesicular monoamine transporter VMAT2 or aromatic acid decarboxylase (AADC; Bjorklund and Dunnett, 2007) and in some cases, fibers have lost TH expression but kept their ability for retrograde transport (Sauer and Oertel, 1994). Therefore, it cannot be excluded that the loss of TH expression observed in these patients could reflect a diseased state rather than the absence of putaminal innervation.

Why was NRTN not transported? A plausible hypothesis is that alpha-synuclein oligomers characteristic of early $\mathrm{PD}$ neuropathology (Schulz-Schaeffer, 2015), accumulating in the axons empede trafficking of the signaling endosomes. Indeed, in dementia with Lewy bodies, the greatest abundance of alphasynuclein aggregates is found in the axons, more particularly in the pre-synaptic terminals (Kramer and Schulz-Schaeffer, 2007) causing synaptic pathology and loss of dendritic spines in the postsynaptic area.

Interestingly, alpha-synuclein fibrils have been shown to interfere with the trafficking of the BDNF/Trk-B signaling endosome (Watson et al., 1999; Volpicelli-Daley et al., 2014). Whether, like these neurotrophins, GFR- $\alpha$ ligands such as GDNF and NRTN exert their survival effect on dopaminergic neurons by a terminally-initiated signaling cascade is still unclear. Indeed, data obtained in compartmentalized cultures of sympathetic and dorsal root ganglia sensory neurons, suggested that GDNF prosurvival effect was predominantly related to a direct cell soma and a terminally-induced Ret-signaling, respectively, thus pointing to a cell type-specific GDNF protective mechanism (Tsui and Pierchala, 2010).

On the other hand, it has been suggested that in the absence of functional nigro-striatal fibers, GDNF expressed in striatal medium spiny neurons can be anterogradely transported to the $\mathrm{SNpr}$ and bind to its receptor in the neighboring $\mathrm{SNpc}$, thus providing a trophic effect (Kells et al., 2010). However, other pre-clinical data have suggested that applying GDNF at the level of the SN could be deleterious either reducing the benefit of intrastriatal delivery (Kirik et al., 2000) or provoking local aberrant sprouting (Georgievska et al., 2002a). In accordance with these studies, in a subsequent clinical trial, two-sites rAAV2NRTN delivery into both putamen and SNpc provided no clinical benefit (Warren Olanow et al., 2015).

Since the rAAV2 vectors used in the clinical trials transduce both interneurons and projection neurons, discriminating between a retrograde signaling mechanism and anterograde transport followed by a local signaling at the soma level has not been feasible. Interestingly, in the adult brain, GDNF is expressed by parvalbumin -positive interneurons (Hidalgo-Figueroa et al., 2012) which are distributed throughout the striatum in a topology which coincides with the distribution of dopaminergic neurons terminals. In this respect, GDNF delivery via AAV2mediated gene transfer does not recapitulate the physiological GDNF secretion.

Strategies targeting separately either interneurons or striatonigral projection neurons could help to unravel the mechanism of the neurotrophic effect and design more promising therapeutical approaches.

Finally, if the nigrostriatal projections are not simply dysfunctional but degenerated and thus absent from the putamen, it is likely that terminally-administered neurotrophic factors will fail to rescue a functional nigro-striatal pathway.

\section{Lack of Predictability of Pre-clinical Animal Models?}

The clinical data were not predicted by the pre-clinical animal models generated by the Ceregene group. Indeed, in the acute MPTP-induced macaque model described by Bartus and collaborators (Bartus et al., 2011), the surviving nigro-striatal 
dopaminergic neurons still had functional projections, proficient for retrograde transport. In contrast, in the patients samples, $<1 \%$ of surviving melanin-positive neurons in the SNpc were costaining with NRTN at 1.5 and 3 months post-surgery and about $5 \%$ at 4 years post-surgery.

These data emphasize the need to perform pre-clinical studies in animal models which recapitulate the progression of the pathology taking into account recent basic research. Indeed, accumulating evidence suggest that $\mathrm{PD}$ neurodegeneration is initiated in axon terminals (Schulz-Schaeffer, 2015). Several authors reported neuropathological hallmarks matching with this mechanism in animal models. Indeed, in a chronic and progressive MPTP-induced macaque model described by the Bezard's group, at the mean onset of Parkinsonian symptoms, striatal DAT binding and DA content decreased to, respectively, 20 and $18 \%$ of untreated monkeys while $57 \%$ of nigral THpositive neurons were spared (Meissner et al., 2003).

Interestingly, the Krystof Bankiewicz group has compared the effects of intraputaminal AAV2-GDNF injection in a mild and an almost complete MPTP lesion in the macaque (Kells et al., 2010). They have evidenced functional improvements (as evidenced by positron emission tomography with 6-[18F]fluoro1 -m-tyrosine scans) and increased TH putaminal innervation and SNpc labellings with both types of lesions. The dopaminergic activities and TH-positive fibers increase in the nearly complete lesion paradigm, were significantly increased but nevertheless only localized in a restricted region of the putamen. These data are in accordance with the post-mortem analysis of patients at 4 years post-injection of rAAV2-NRTN, in which, despite the nearly total absence of TH staining in the putamen, a TH-positive innervation appeared in a limited area in the vicinity of the vector injection (Bartus et al., 2015).

In addition to phenotypic toxin-induced models, genetic models based on the transgenic expression of mutants isolated in familial PD cases provide valuable tools to evaluate gene therapy approaches. Notably, in a virally-mediated local alpha-synuclein transgenes is, as observed in patients populations (Kordower et al., 2013), axonopathy preceeded neuronal cell death (GarciaReitbock et al., 2010; Van der Perren et al., 2015). Intriguingly, GDNF had no effect on dopaminergic neuron survival and motor symptoms in two different local, intranigral alpha-synuclein transgenic models: a lentiviral vector mediated expression of the human A30P mutant in mice (Lo Bianco et al., 2004) and a rAAVmediated overexpression of human wild-type alpha-synuclein in rats (Decressac et al., 2011). This failure has been attributed to Ret downregulation and disruption of GDNF signaling due to Nurr1 downregulation induced by alpha-synuclein overexpression (Decressac et al., 2012). However, it should be noted that, in contrast to this report, two other studies showed that neither RET protein, nor Ret mRNA are downregulated in patients with Lewy bodies (Walker et al., 1998; Backman et al., 2006). It might be that the concentration of intranigral alpha-synuclein protein expressed by the viral vectors was higher than in PD patients and induced collateral effects (Hoffer and Harvey, 2011). The quantitative evaluation of alpha-synuclein content in Parkinson's disease patients post-mortem tissue has proven difficult due to the existence of multiple alpha-synuclein forms and difficulties in solubilizing these proteins. In one study, membrane-associated sodium dodecyl sulfate soluble full-length $17 \mathrm{kDa}$ and high molecular weight alpha-synuclein species were only slightly increased in PD patients as compared to healthy subjects (Tong et al., 2010) whereas in another study total alphasynuclein was suggested to be 11-fold increased in fresh frozen protein extracts (Shehadeh et al., 2009). Since the proportion of monomeric vs. multimeric alpha-synuclein species as well as their conformation, which play an important role in toxic effects (Peelaerts et al., 2015), were not quantified separately, it is difficult to evaluate the predictive value of the animal models.

In the study by Decressac et al. $(2011,2012)$ the alphasynuclein concentration in the substantia nigra of the rAAVinjected rats has not been reported. In other studies using rAAV vectors, the alpha-synuclein levels were found to be three- to four-fold increased (Gorbatyuk et al., 2010; Landeck et al., 2017). However, since the AAV vector serotype, the viral preparation titer and the promoter used for transgene expression differed from those used in the study by Decressac et al. $(2011,2012)$ these data cannot possibly be compared to the patients data. In addition, it has recently been shown that in contrast to virallydelivered human alpha-synuclein, rat alpha-synuclein induced no detectable neurodegeneration at similar vector doses. These data are questioning the conclusions of studies using human alpha-synuclein in rodent models.

Physiologically, alpha-synuclein-mediated SNARE-complex assembly is necessary for synaptic function but at high doses, alpha-synuclein pathologically misfolds into neurotoxic forms. Accordingly, alpha-synuclein has been shown to inhibit synaptic vesicle exocytosis in transfected midbrain dopaminergic neurons cultures in a dose-response manner (Burre et al., 2010; Lundblad et al., 2012). Toxic alpha-synuclein fibrils was also shown to impair the retrograde transport of BDNF signaling endosome (Volpicelli-Daley et al., 2014). Whether, in the study by Decressac et al. (2011), alpha-synuclein overexpression (Nemani et al., 2010), in addition to reducing the Ret signaling cascade (Decressac et al., 2012) also resulted in (i) a reduction of DA release and re-uptake and/or (ii) blocked GDNF retrograde transport has not been investigated (Lundblad et al., 2012; See also reference (Hoffer and Harvey, 2011) for an extensive discussion about the potential pitfalls of the rAAV-mediated alpha-synuclein model for the evaluation of the therapeutical effect of GDNF gene delivery). Interestingly, injection of preformed $\alpha$-synuclein fibrils seemed to faithfully recapitulate the hallmarks of the pathology (Volpicelli-Daley et al., 2014, 2016).

Finally, transgenic mice harboring a mutant LRRK2 gene (the most frequent mutation in PD) also provides an interesting, potentially clinically-relevant, phenotype. Indeed, in this model no loss of dopaminergic neuron cell bodies was observed, whereas axons harbored dystrophic neuritis (Li et al., 2009).

\section{Neurturin vs. GDNF}

Pre-clinical studies established the neuroprotective potential of NRTN gene delivery (Fjord-Larsen et al., 2005; Kordower et al., 2006; Gasmi et al., 2007a,b; Herzog et al., 2009). However, the amount of basic knowledge about NRTN is far less abundant than 
for GDNF and outlines important differences between the two neurotrophic factors.

First, the induction of Ret-mediated signaling is expected to be far less efficient after NRTN as compared to GDNF gene delivery. Indeed, dopaminergic neurons express GFR- $\alpha 1$ but not GFR- $\alpha 2$, the preferred NRTN primary receptor. NRTN can bind to GFR$\alpha 1$ but with a much lower affinity than GDNF (Kramer and Liss, 2015). In addition, NRTN diffuses less efficiently than GDNF in the parenchyma (Runeberg-Roos et al., 2016). Finally, contrarily to GDNF, NRTN endogenous secretion signal is weak and in order to reach efficiency, in the genetic construct developed for gene therapy, it has been replaced by a mice immunoglobulin signal peptide (Fjord-Larsen et al., 2005).

\section{Delivery Issues: Poor Coverage of the Target Structure}

The rAAV2 viral particles (Nguyen et al., 2001; Burger et al., 2004; Hadaczek et al., 2006; Lubansu et al., 2008) as well as NRTN itself (Bespalov et al., 2011) poorly diffuse in the brain parenchyma. Post-mortem analyses showed that only $\sim 15 \%$ of the putamen was covered with NRTN (Bartus et al., 2011), which could be suboptimal to observe a significant therapeutical effect. Therefore, interpretation of clinical and histopathological data from the rAAV2-NRTN clinical trials should be taken with caution.

NRTN binds to heparan sulfate, which severely reduces its diffusion (Bespalov et al., 2011). Recently, NRTN mutants (mutated in heparan sulfate binding sites) were shown to diffuse further away from the delivery site and to be more neuroprotective in the 6-OHDA model (Runeberg-Roos et al., 2016). The use of optimized neurosurgical techniques could further help overcoming this limitation (Johnston et al., 2009).

\section{Delivery Issues: Long-Term Uninterrupted GDNF Treatment Induces Compensatory Effects}

In preclinical models, compensatory effects reducing the expression of enzymes of the DA biosynthesis pathway (Georgievska et al., 2002a; Chtarto et al., 2007) as well as of DAT activity (Barroso-Chinea et al., 2016) appeared after long-term continuous treatment with GDNF. These neurochemical effects are likely to interfere with neurotrophic effects and possibly reduce clinical benefits. Interestingly, pulses of GDNF delivery provided similar neuroprotection as a continuous treatment while avoiding TH downregulation (Tereshchenko et al., 2014). Therefore, repeated short-term expression rather that continuous GDNF administration might constitute the treatment of choice for $\mathrm{PD}$.

\section{TIME TO REVISIT GDNF GENE THERAPY PARADIGM?}

\section{Taking into Account Early Axonopathy}

Novel knowledge indicates that PD neurodegeneration is initiated at the level of the terminals and that neuron cell death is a remote consequence of synaptic dysfunction rather than a primary event. Therefore, whether GFR- $\alpha$ ligands in complex with Ret, activating anti-apoptotic and neurotrophic signaling cascades, constitute a relevant disease-modifying tool could be questioned.

In advanced patients (from 5 years post-diagnosis), TH-positive putaminal innervation has almost completely disappeared (Kordower et al., 2013). rAAV2-NRTN administered at least 5-years post-diagnosis (Marks et al., 2008) failed to provide a clear significant clinical benefit (Marks et al., 2010). In a subsequent clinical trial combining intraputaminal and intranigral vector administration, less advanced patients were included (Warren Olanow et al., 2015). A post-hoc analysis including the patients into subgroups according to the advancement of the disease at the time of surgery, seemed to indicate that the therapy could have benefited to less advanced patients (Bartus and Johnson, 2017a,b).

\section{Effects of GDNF on Dopaminergic Neurotransmission}

As outlined above, GDNF mediates neurochemical effects either augmenting the dopaminergic function or inducing compensatory mechanisms reducing the dopaminergic function. These effects may play an important role in the observed beneficial effects on motor symptoms in pre-clinical studies and possibly in clinical studies (Marks et al., 2010; Bartus et al., 2014). Further studies dissecting the mechanism of specific GDNF functional effects are required in order to interprete the clinical data and possibly design new viral vectors and clinical protocols fully exploiting the neuroprotective effects of GDNF while avoiding confounding effects.

\section{Avoid Undesirable Compensatory Effects of Sustained GDNF Administration at Supraphysiological Doses}

Except in one study (Eslamboli et al., 2005), in which GDNF striatal concentration was only three-fold higher than the endogenous level, in most preclinical studies it was increased at least 10-fold (Kirik et al., 2000; Georgievska et al., 2002a; Yang et al., 2009). In such conditions of excessive GDNF overexpression, time-dependent compensatory mechanisms affecting both the motor behavior and DA biosynthesis and turn-over were observed (Kirik et al., 2000; Georgievska et al., 2002a; Yang et al., 2009). Therefore, GDNF administration should be adjusted to a concentration which does not perturb DA homeostasis and the treatment should be interrupted before the appearance of compensatory effects.

\section{Physiological GDNF Secretory Pathway}

GDNF secretion can either be constitutive or regulated by depolarization and $\mathrm{Ca}^{2+}$ entry (Lonka-Nevalaita et al., 2010). In the rodent striatum, GDNF is natively expressed by parvalbumin interneurons (Hidalgo-Figueroa et al., 2012; d'Anglemont de Tassigny et al., 2015) which are fast spiking neurons, controlling the activity of medium spiny neurons 
of the direct and indirect pathways and closely associated with dopaminergic neurons terminals (d'Anglemont de Tassigny et al., 2015). None of the viral vectors used so far provides a targeted transgene expression into parvalbumin interneurons.

\section{Future Directions}

Although, the results of clinical trials using GDNF recombinant protein or NRTN gene delivery for PD patients have so far been disappointing, evolving basic knowledge on PD physiopathology and GDNF biology as well as improvements of viral vectors technology justify pursuing neuroprotective approaches. However, understanding the respective dose range, kinetics and cellular specificity of neurotrophic and neurochemical effects and adapting the amounts of neurotrophic factor administered and the periods of treatment will be of utmost importance for the success of this emerging disease-modifying treatment.

Regardless, the recent data showing that TH-positive putaminal innervation has almost completely disappeared at 5 years post-diagnosis, questions the feasibility of treating advanced patients with neurotrophic factors. Hopefully, the demonstration of the safety of rAAV administration into the human brain (Kaplitt et al., 2007; Marks et al., 2008; LeWitt et al., 2011; Leone et al., 2012; Bartus et al., 2013; Tardieu et al., 2014; Warren Olanow et al., 2015) will pave the way for new trials enrolling less advanced patients.

\section{REFERENCES}

Airavaara, M., Planken, A., Gaddnas, H., Piepponen, T. P., Saarma, M., and Ahtee, L. (2004). Increased extracellular dopamine concentrations and FosB/DeltaFosB expression in striatal brain areas of heterozygous GDNF knockout mice. Eur. J. Neurosci. 20, 2336-2344. doi: 10.1111/j.1460-9568.2004.03700.x

Backman, C. M., Shan, L., Zhang, Y. J., Hoffer, B. J., Leonard, S., Troncoso, J. C., et al. (2006). Gene expression patterns for GDNF and its receptors in the human putamen affected by Parkinson's disease: a real-time PCR study. Mol. Cell. Endocrinol. 252, 160-166. doi: 10.1016/j.mce.2006.03.013

Barroso-Chinea, P., Cruz-Muros, I., Afonso-Oramas, D., Castro-Hernandez, J., Salas-Hernandez, J., Chtarto, A., et al. (2016). Long-term controlled GDNF over-expression reduces dopamine transporter activity without affecting tyrosine hydroxylase expression in the rat mesostriatal system. Neurobiol. Dis. 88, 44-54. doi: 10.1016/j.nbd.2016.01.002

Bartus, R. T., Baumann, T. L., Siffert, J., Herzog, C. D., Alterman, R., Boulis, N., et al. (2013). Safety/feasibility of targeting the substantia nigra with AAV2-neurturin in Parkinson patients. Neurology 80, 1698-1701. doi: 10.1212/WNL.0b013e3182904faa

Bartus, R. T., Herzog, C. D., Chu, Y., Wilson, A., Brown, L., Siffert, J., et al. (2011). Bioactivity of AAV2-neurturin gene therapy (CERE-120): differences between Parkinson's disease and nonhuman primate brains. Mov. Disord. 26, 27-36. doi: $10.1002 / \mathrm{mds} .23442$

Bartus, R. T., and Johnson, E. M. Jr. (2017a). Clinical tests of neurotrophic factors for human neurodegenerative diseases, part 1: where have we been and what have we learned? Neurobiol. Dis. 97(Pt B), 156-168. doi: 10.1016/j.nbd.2016.03.027

Bartus, R. T., and Johnson, E. M. Jr. (2017b). Clinical tests of neurotrophic factors for human neurodegenerative diseases, part 2: where do we stand and where must we go next? Neurobiol. Dis. 97(Pt B), 169-178. doi: 10.1016/j.nbd.2016.03.026

\section{AUTHOR CONTRIBUTIONS}

LT wrote the review and critically read the table and figure. $\mathrm{MH}$ made the table and the figure and critically read the manuscript.

\section{ACKNOWLEDGMENTS}

This work was supported by EU FP7 Marie Curie IndustryAcademy Partnerships and Pathways grant (contract $\mathrm{n}^{\circ} 286071$; http://www.brainvectors.org) by the Swiss National Research Foundation (grant $\mathrm{n}^{\circ}$ FN31003A-127177) and by uniQure, N.V. We thank Tomas Gonzales-Hernandez (Univ. Teneriffe), Mikko Airavaara and Mart Saarma (University of Helsinki) as well as all partners of the BrainVectors consortium for stimulating and fruitful interactions. We also thank Jolanda Liefhebber, Pavlina Konstantinova, Bas Blits, and Harald Petry (uniQure) for their collaboration on regulated vectors for GDNF delivery. Some parts of this manuscript rely on discussions between experts gathered in a workshop held in Lausanne University Hospital on 12-14 September 2016 (http://www.brainvectors.org). We also thank Raymond Bartus (RTBioconsultants, Inc.) for deep and enlighting discussions preceeding the workshop. This meeting was supported by the Swiss National Research Foundation (grant $n^{\circ}$ 286071), by the Swiss Parkinson Foundation (http://www.parkinson.ch/), by Medtronic (http://www.medtronic.ch) and by the European Association for Scientific Career Orientation (http://www.EASCO.org).

Bartus, R. T., Kordower, J. H., Johnson, E. M. Jr., Brown, L., Kruegel, B. R., Chu, Y., et al. (2015). Post-mortem assessment of the short and long-term effects of the trophic factor neurturin in patients with $\alpha$-synucleinopathies. Neurobiol. Dis. 78, 162-171. doi: 10.1016/j.nbd.2015.03.023

Bartus, R. T., Weinberg, M. S., and Samulski, R. J. (2014). Parkinson's disease gene therapy: success by design meets failure by efficacy. Mol. Ther. 22, 487-497. doi: $10.1038 / \mathrm{mt} .2013 .281$

Bensadoun, J. C., Deglon, N., Tseng, J. L., Ridet, J. L., Zurn, A. D., and Aebischer, P. (2000). Lentiviral vectors as a gene delivery system in the mouse midbrain: cellular and behavioral improvements in a 6-OHDA model of Parkinson's disease using GDNF. Exp. Neurol. 164, 15-24. doi: 10.1006/exnr.20 00.7409

Bespalov, M. M., Sidorova, Y. A., Tumova, S., Ahonen-Bishopp, A., Magalhaes, A. C., Kulesskiy, E., et al. (2011). Heparan sulfate proteoglycan syndecan-3 is a novel receptor for GDNF, neurturin, and artemin. J. Cell Biol. 192, 153-169. doi: $10.1083 /$ jcb. 201009136

Bilang-Bleuel, A., Revah, F., Colin, P., Locquet, I., Robert, J. J., Mallet, J., et al. (1997). Intrastriatal injection of an adenoviral vector expressing glial-cell-linederived neurotrophic factor prevents dopaminergic neuron degeneration and behavioral impairment in a rat model of Parkinson disease. Proc. Natl. Acad. Sci. U.S.A. 94, 8818-8823. doi: 10.1073/pnas.94.16.8818

Bjorklund, A., and Dunnett, S. B. (2007). Dopamine neuron systems in the brain: an update. Trends Neurosci. 30, 194-202. doi: 10.1016/j.tins.2007.03.006

Bockstael, O., Chtarto, A., Wakkinen, J., Yang, X., Melas, C., Levivier, M., et al. (2008). Differential transgene expression profiles in rat brain, using rAAV2/1 vectors with tetracycline-inducible and cytomegalovirus promoters. Hum. Gene Ther. 19, 1293-1305. doi: 10.1089/hum.2008.099

Boger, H. A., Middaugh, L. D., Patrick, K. S., Ramamoorthy, S., Denehy, E. D., Zhu, H., et al. (2007). Long-term consequences of methamphetamine exposure in young adults are exacerbated in glial cell line-derived neurotrophic factor heterozygous mice. J. Neurosci. 27, 8816-8825. doi: 10.1523/JNEUROSCI.1067-07.2007 
Bourque, M. J., and Trudeau, L. E. (2000). GDNF enhances the synaptic efficacy of dopaminergic neurons in culture. Eur. J. Neurosci. 12, 3172-3180. doi: 10.1046/j.1460-9568.2000.00219.x

Brizard, M., Carcenac, C., Bemelmans, A. P., Feuerstein, C., Mallet, J., and Savasta, M. (2006). Functional reinnervation from remaining DA terminals induced by GDNF lentivirus in a rat model of early Parkinson's disease. Neurobiol. Dis. 21, 90-101. doi: 10.1016/j.nbd.2005.06.015

Burger, C., Gorbatyuk, O. S., Velardo, M. J., Peden, C. S., Williams, P., Zolotukhin, S., et al. (2004). Recombinant AAV viral vectors pseudotyped with viral capsids from serotypes 1,2 , and 5 display differential efficiency and cell tropism after delivery to different regions of the central nervous system. Mol. Ther. 10, 302-317. doi: 10.1016/j.ymthe.2004.05.024

Burke, R. E., and O'Malley, K. (2013). Axon degeneration in Parkinson's disease. Exp. Neurol. 246, 72-83. doi: 10.1016/j.expneurol.2012.01.011

Burre, J., Sharma, M., Tsetsenis, T., Buchman, V., Etherton, M. R., and Sudhof, T. C. (2010). $\alpha$-synuclein promotes SNARE-complex assembly in vivo and in vitro. Science 329, 1663-1667. doi: 10.1126/science.1195227

Chauhan, N. B., Siegel, G. J., and Lee, J. M. (2001). Depletion of glial cell linederived neurotrophic factor in substantia nigra neurons of Parkinson's disease brain. J. Chem. Neuroanat. 21, 277-288. doi: 10.1016/S0891-0618(01)00115-6

Choi-Lundberg, D. L., Lin, Q., Chang, Y. N., Chiang, Y. L., Hay, C. M., Mohajeri, H., et al. (1997). Dopaminergic neurons protected from degeneration by GDNF gene therapy. Science 275, 838-841. doi: 10.1126/science.275.5301.838

Chtarto, A., Humbert-Claude, M., Bockstael, O., Das, A. T., Boutry, S., Breger, L. S., et al. (2016). A regulatable AAV vector mediating GDNF biological effects at clinically-approved sub-antimicrobial doxycycline doses. Mol. Ther. Methods Clin. Dev. 5:16027. doi: 10.1038/mtm.2016.27

Chtarto, A., Yang, X., Bockstael, O., Melas, C., Blum, D., Lehtonen, E., et al. (2007). Controlled delivery of glial cell line-derived neurotrophic factor by a single tetracycline-inducible AAV vector. Exp. Neurol. 204, 387-399. doi: 10.1016/j.expneurol.2006.11.014

Connor, B., Kozlowski, D. A., Schallert, T., Tillerson, J. L., Davidson, B. L., and Bohn, M. C. (1999). Differential effects of glial cell line-derived neurotrophic factor (GDNF) in the striatum and substantia nigra of the aged Parkinsonian rat. Gene Ther. 6, 1936-1951. doi: 10.1038/sj.gt.3301033

d'Anglemont de Tassigny, X., Pascual, A., and Lopez-Barneo, J. (2015). GDNFbased therapies, GDNF-producing interneurons, and trophic support of the dopaminergic nigrostriatal pathway. Implications for Parkinson's disease. Front. Neuroanat. 9:10. doi: 10.3389/fnana.2015.00010

Decressac, M., Kadkhodaei, B., Mattsson, B., Laguna, A., Perlmann, T., and Bjorklund, A. (2012). $\alpha$-Synuclein-induced down-regulation of Nurr1 disrupts GDNF signaling in nigral dopamine neurons. Sci. Transl. Med. 4, 163 ra156. doi: 10.1126/scitranslmed.3004676

Decressac, M., Ulusoy, A., Mattsson, B., Georgievska, B., Romero-Ramos, M., Kirik, D., et al. (2011). GDNF fails to exert neuroprotection in a rat $\alpha$-synuclein model of Parkinson's disease. Brain 134, 2302-2311. doi: 10.1093/brain/ awr149

Do Thi, N. A., Saillour, P., Ferrero, L., Dedieu, J. F., Mallet, J., and Paunio, T. (2004). Delivery of GDNF by an E1,E3/E4 deleted adenoviral vector and driven by a GFAP promoter prevents dopaminergic neuron degeneration in a rat model of Parkinson's disease. Gene Ther. 11, 746-756. doi: 10.1038/sj.gt.3302222

Drinkut, A., Tereshchenko, Y., Schulz, J. B., Bahr, M., and Kugler, S. (2012). Efficient gene therapy for Parkinson's disease using astrocytes as hosts for localized neurotrophic factor delivery. Mol. Ther. 20, 534-543. doi: 10.1038/mt.2011.249

Eberling, J. L., Kells, A. P., Pivirotto, P., Beyer, J., Bringas, J., Federoff, H. J., et al. (2009). Functional effects of AAV2-GDNF on the dopaminergic nigrostriatal pathway in parkinsonian rhesus monkeys. Hum. Gene Ther. 20, 511-518. doi: 10.1089/hum.2008.201

Eslamboli, A., Cummings, R. M., Ridley, R. M., Baker, H. F., Muzyczka, N., Burger, C., et al. (2003). Recombinant adeno-associated viral vector (rAAV) delivery of GDNF provides protection against 6-OHDA lesion in the common marmoset monkey (Callithrix jacchus). Exp. Neurol. 184, 536-548. doi: 10.1016/j.expneurol.2003.08.007

Eslamboli, A., Georgievska, B., Ridley, R. M., Baker, H. F., Muzyczka, N., Burger, C., et al. (2005). Continuous low-level glial cell line-derived neurotrophic factor delivery using recombinant adeno-associated viral vectors provides neuroprotection and induces behavioral recovery in a primate model of Parkinson's disease. J. Neurosci. 25, 769-777. doi: 10.1523/JNEUROSCI.4421-04.2005

Fjord-Larsen, L., Johansen, J. L., Kusk, P., Tornoe, J., Gronborg, M., Rosenblad, C., et al. (2005). Efficient in vivo protection of nigral dopaminergic neurons by lentiviral gene transfer of a modified Neurturin construct. Exp. Neurol. 195, 49-60. doi: 10.1016/j.expneurol.2005.03.006

Garcia-Reitbock, P., Anichtchik, O., Bellucci, A., Iovino, M., Ballini, C., Fineberg, E., et al. (2010). SNARE protein redistribution and synaptic failure in a transgenic mouse model of Parkinson's disease. Brain 133, 2032-2044. doi: 10.1093/brain/awq132

Gasmi, M., Brandon, E. P., Herzog, C. D., Wilson, A., Bishop, K. M., Hofer, E. K., et al. (2007b). AAV2-mediated delivery of human neurturin to the rat nigrostriatal system: long-term efficacy and tolerability of CERE-120 for Parkinson's disease. Neurobiol. Dis. 27, 67-76. doi: 10.1016/j.nbd.2007.04.003

Gasmi, M., Herzog, C. D., Brandon, E. P., Cunningham, J. J., Ramirez, G. A., Ketchum, E. T., et al. (2007a). Striatal delivery of neurturin by CERE-120, an AAV2 vector for the treatment of dopaminergic neuron degeneration in Parkinson's disease. Mol. Ther. 15, 62-68. doi: 10.1038/sj.mt.6300010

Georgievska, B., Jakobsson, J., Persson, E., Ericson, C., Kirik, D., and Lundberg, C. (2004). Regulated delivery of glial cell line-derived neurotrophic factor into rat striatum, using a tetracycline-dependent lentiviral vector. Hum. Gene Ther. 15, 934-944. doi: 10.1089/hum.2004.15.934

Georgievska, B., Kirik, D., and Bjorklund, A. (2002a). Aberrant sprouting and downregulation of tyrosine hydroxylase in lesioned nigrostriatal dopamine neurons induced by long-lasting overexpression of glial cell line derived neurotrophic factor in the striatum by lentiviral gene transfer. Exp. Neurol. 177, 461-474. doi: 10.1006/exnr.2002.8006

Georgievska, B., Kirik, D., Rosenblad, C., Lundberg, C., and Bjorklund, A. (2002b). Neuroprotection in the rat Parkinson model by intrastriatal GDNF gene transfer using a lentiviral vector. Neuroreport 13, 75-82. doi: 10.1097/00001756-200201210-00019

Gorbatyuk, O. S., Li, S., Nguyen, F. N., Manfredsson, F. P., Kondrikova, G., Sullivan, L. F., et al. (2010). $\alpha$-Synuclein expression in rat substantia nigra suppresses phospholipase D2 toxicity and nigral neurodegeneration. Mol. Ther. 18, 1758-1768. doi: 10.1038/mt.2010.137

Gordon, S. L., Quinsey, N. S., Dunkley, P. R., and Dickson, P. W. (2008). Tyrosine hydroxylase activity is regulated by two distinct dopamine-binding sites. J. Neurochem. 106, 1614-1623. doi: 10.1111/j.1471-4159.2008.05509.x

Hadaczek, P., Yamashita, Y., Mirek, H., Tamas, L., Bohn, M. C., Noble, C., et al. (2006). The "perivascular pump" driven by arterial pulsation is a powerful mechanism for the distribution of therapeutic molecules within the brain. Mol. Ther. 14, 69-78. doi: 10.1016/j.ymthe.2006.02.018

Hebert, M. A., Van Horne, C. G., Hoffer, B. J., and Gerhardt, G. A. (1996) Functional effects of GDNF in normal rat striatum: presynaptic studies using in vivo electrochemistry and microdialysis. J. Pharmacol. Exp. Ther. 279, 1181-1190.

Herzog, C. D., Brown, L., Gammon, D., Kruegel, B., Lin, R., Wilson, A., et al. (2009). Expression, bioactivity, and safety 1 year after adeno-associated viral vector type 2-mediated delivery of neurturin to the monkey nigrostriatal system support cere-120 for Parkinson's disease. Neurosurgery 64, 602-612; discussion: 612-603. doi: 10.1227/01.neu.0000340682.06068.01

Herzog, C. D., Dass, B., Gasmi, M., Bakay, R., Stansell, J. E., Tuszynski, M., et al. (2008). Transgene expression, bioactivity, and safety of CERE-120 (AAV2-neurturin) following delivery to the monkey striatum. Mol. Ther. 16, 1737-1744. doi: 10.1038/mt.2008.170

Hidalgo-Figueroa, M., Bonilla, S., Gutierrez, F., Pascual, A., and LopezBarneo, J. (2012). GDNF is predominantly expressed in the PV+ neostriatal interneuronal ensemble in normal mouse and after injury of the nigrostriatal pathway. J. Neurosci. 32, 864-872. doi: 10.1523/JNEUROSCI.2693-11.2012

Hoffer, B. J., and Harvey, B. K. (2011). Is GDNF beneficial in Parkinson disease? Nat. Rev. Neurol. 7, 600-602. doi: 10.1038/nrneurol.2011.149.

Hudson, J., Granholm, A.-C., Gerhardt, G. A., Henry, M. A., Hoffman, A., Biddle, P., et al. (1995). Glial cell line-derived neurotrophic factor augments midbrain dopaminergic circuits in vivo. Brain Res. Bull. 36, 425-432. doi: 10.1016/0361-9230(94)00224-O

Jing, S., Yu, Y., Fang, M., Hu, Z., Holst, P. L., Boone, T., et al. (1997). GFR $\alpha-2$ and GFR $\alpha-3$ are two new receptors for ligands of the GDNF family. J. Biol. Chem. 272, 33111-33117. doi: 10.1074/jbc.272.52.33111 
Johnston, L. C., Eberling, J., Pivirotto, P., Hadaczek, P., Federoff, H. J., Forsayeth, J., et al. (2009). Clinically relevant effects of convection-enhanced delivery of AAV2-GDNF on the dopaminergic nigrostriatal pathway in aged rhesus monkeys. Hum. Gene Ther. 20, 497-510. doi: 10.1089/hum.2008.137

Kaplitt, M. G., Feigin, A., Tang, C., Fitzsimons, H. L., Mattis, P., Lawlor, P. A., et al. (2007). Safety and tolerability of gene therapy with an adeno-associated virus (AAV) borne GAD gene for Parkinson's disease: an open label, phase I trial. Lancet 369, 2097-2105. doi: 10.1016/S0140-6736(07)60982-9

Kells, A. P., Eberling, J., Su, X., Pivirotto, P., Bringas, J., Hadaczek, P., et al. (2010). Regeneration of the MPTP-lesioned dopaminergic system after convection-enhanced delivery of AAV2-GDNF. J. Neurosci. 30, 9567-9577. doi: 10.1523/JNEUROSCI.0942-10.2010

Kirik, D., Rosenblad, C., Bjorklund, A., and Mandel, R. J. (2000). Long-term rAAVmediated gene transfer of GDNF in the rat Parkinson's model: intrastriatal but not intranigral transduction promotes functional regeneration in the lesioned nigrostriatal system. J. Neurosci. 20, 4686-4700.

Kopra, J., Vilenius, C., Grealish, S., Harma, M. A., Varendi, K., Lindholm, J., et al. (2015). GDNF is not required for catecholaminergic neuron survival in vivo. Nat. Neurosci. 18, 319-322. doi: 10.1038/nn.3941

Kordower, J. H., Emborg, M. E., Bloch, J., Ma, S. Y., Chu, Y., Leventhal, L., et al. (2000). Neurodegeneration prevented by lentiviral vector delivery of GDNF in primate models of Parkinson's disease. Science 290, 767-773. doi: $10.1126 /$ science. 290.5492 .767

Kordower, J. H., Herzog, C. D., Dass, B., Bakay, R. A., Stansell, J. III, Gasmi, M., et al. (2006). Delivery of neurturin by AAV2 (CERE-120)mediated gene transfer provides structural and functional neuroprotection and neurorestoration in MPTP-treated monkeys. Ann. Neurol. 60, 706-715. doi: $10.1002 /$ ana. 21032

Kordower, J. H., Olanow, C. W., Dodiya, H. B., Chu, Y., Beach, T. G., Adler, C. H., et al. (2013). Disease duration and the integrity of the nigrostriatal system in Parkinson's disease. Brain 136, 2419-2431. doi: 10.1093/brain/ awt 192

Kozlowski, D. A., Connor, B., Tillerson, J. L., Schallert, T., and Bohn, M. C. (2000). Delivery of a GDNF gene into the substantia nigra after a progressive 6-OHDA lesion maintains functional nigrostriatal connections. Exp. Neurol. 166, 1-15. doi: 10.1006/exnr.2000.7463

Kramer, E. R., Aron, L., Ramakers, G. M., Seitz, S., Zhuang, X., Beyer, K., et al. (2007). Absence of Ret signaling in mice causes progressive and late degeneration of the nigrostriatal system. PLoS Biol. 5:e39. doi: 10.1371/journal.pbio.0050039

Kramer, E. R., and Liss, B. (2015). GDNF-Ret signaling in midbrain dopaminergic neurons and its implication for Parkinson disease. FEBS Lett. 589, 3760-3772. doi: 10.1016/j.febslet.2015.11.006

Kramer, M. L., and Schulz-Schaeffer, W. J. (2007). Presynaptic $\alpha$-synuclein aggregates, not Lewy bodies, cause neurodegeneration in dementia with Lewy bodies. J. Neurosci. 27, 1405-1410. doi: 10.1523/JNEUROSCI.4564-06.2007

Kumar, A., Kopra, J., Varendi, K., Porokuokka, L. L., Panhelainen, A., Kuure, S., et al. (2015). GDNF overexpression from the native locus reveals its role in the nigrostriatal dopaminergic system function. PLoS Genet. 11:e1005710. doi: 10.1371/journal.pgen.1005710

Kurowska, Z., Kordower, J. H., Stoessl, A. J., Burke, R., Brundin, P., Yue, Z., et al. (2016). Is axonal degeneration a key early event in parkinson's disease? J. Parkinsons Dis. 6, 703-707. doi: 10.3233/JPD-160881

Landeck, N., Buck, K., and Kirik, D. (2017). Toxic effects of human and rodent variants of alpha-synuclein in vivo. Eur. J. Neurosci. 45, 536-547. doi: $10.1111 /$ ejn.13493

Lang, A. E., Gill, S., Patel, N. K., Lozano, A., Nutt, J. G., Penn, R., et al. (2006). Randomized controlled trial of intraputamenal glial cell line-derived neurotrophic factor infusion in Parkinson disease. Ann. Neurol. 59, 459-466. doi: 10.1002/ana.20737

Leone, P., Shera, D., McPhee, S. W., Francis, J. S., Kolodny, E. H., Bilaniuk, L. T., et al. (2012). Long-term follow-up after gene therapy for canavan disease. Sci. Transl. Med. 4, 165ra163. doi: 10.1126/scitranslmed.3003454

LeWitt, P. A., Rezai, A. R., Leehey, M. A., Ojemann, S. G., Flaherty, A. W., Eskandar, E. N., et al. (2011). AAV2-GAD gene therapy for advanced Parkinson's disease: a double-blind, sham-surgery controlled, randomised trial. Lancet Neurol. 10, 309-319. doi: 10.1016/S1474-4422(11)70039-4
Li, Y., Liu, W., Oo, T. F., Wang, L., Tang, Y., Jackson-Lewis, V., et al. (2009). Mutant LRRK2(R1441G) BAC transgenic mice recapitulate cardinal features of Parkinson's disease. Nat. Neurosci. 12, 826-828. doi: 10.1038/nn.2349

Lin, L. F., Doherty, D. H., Lile, J. D., Bektesh, S., and Collins, F. (1993). GDNF: a glial cell line-derived neurotrophic factor for midbrain dopaminergic neurons. Science 260, 1130-1132. doi: 10.1126/science.8493557

Littrell, O. M., Pomerleau, F., Huettl, P., Surgener, S., McGinty, J. F., Middaugh, L. D., et al. (2012). Enhanced dopamine transporter activity in middle-aged GDNF heterozygous mice. Neurobiol Aging 33, 427.e1-427.e14. doi: 10.1016/j.neurobiolaging.2010.10.013

Lo Bianco, C., Deglon, N., Pralong, W., and Aebischer, P. (2004). Lentiviral nigral delivery of GDNF does not prevent neurodegeneration in a genetic rat model of Parkinson's disease. Neurobiol. Dis. 17, 283-289. doi: 10.1016/j.nbd.2004.06.008 Lonka-Nevalaita, L., Lume, M., Leppanen, S., Jokitalo, E., Peranen, J., and Saarma, M. (2010). Characterization of the intracellular localization, processing, and secretion of two glial cell line-derived neurotrophic factor splice isoforms. J. Neurosci. 30, 11403-11413. doi: 10.1523/JNEUROSCI.5888-09.2010

Lubansu, A., Abeloos, L., Bockstael, O., Lehtonen, E., Blum, D., Brotchi, J., et al. (2008). Recombinant AAV viral vectors serotype 1,2, and 5 mediate differential gene transfer efficiency in rat striatal fetal grafts. Cell Transplant. 16, 1013-1020. doi: $10.3727 / 000000007783472372$

Lundblad, M., Decressac, M., Mattsson, B., and Bjorklund, A. (2012). Impaired neurotransmission caused by overexpression of $\alpha$-synuclein in nigral dopamine neurons. Proc. Natl. Acad. Sci. U.S.A. 109, 3213-3219. doi: 10.1073/pnas.1200575109

Mandel, R. J., Snyder, R. O., and Leff, S. E. (1999). Recombinant adenoassociated viral vector-mediated glial cell line-derived neurotrophic factor gene transfer protects nigral dopamine neurons after onset of progressive degeneration in a rat model of Parkinson's disease. Exp. Neurol. 160, 205-214. doi: 10.1006/exnr.1999.7203

Mandel, R. J., Spratt, S. K., Snyder, R. O., and Leff, S. E. (1997). Midbrain injection of recombinant adeno-associated virus encoding rat glial cell linederived neurotrophic factor protects nigral neurons in a progressive 6hydroxydopamine-induced degeneration model of Parkinson's disease in rats. Proc. Natl. Acad. Sci. U.S.A. 94, 14083-14088. doi: 10.1073/pnas.94.25.14083

Manfredsson, F. P., Tumer, N., Erdos, B., Landa, T., Broxson, C. S., Sullivan, L. F., et al. (2009). Nigrostriatal rAAV-mediated GDNF overexpression induces robust weight loss in a rat model of age-related obesity. Mol. Ther. 17, 980-991. doi: $10.1038 / \mathrm{mt} .2009 .45$

Marks, W. J. Jr., Bartus, R. T., Siffert, J., Davis, C. S., Lozano, A., Boulis, N., et al. (2010). Gene delivery of AAV2-neurturin for Parkinson's disease: a double-blind, randomised, controlled trial. Lancet Neurol. 9, 1164-1172. doi: 10.1016/S1474-4422(10)70254-4

Marks, W. J. Jr., Ostrem, J. L., Verhagen, L., Starr, P. A., Larson, P. S., Bakay, R. A., et al. (2008). Safety and tolerability of intraputaminal delivery of CERE120 (adeno-associated virus serotype 2-neurturin) to patients with idiopathic Parkinson's disease: an open-label, phase I trial. Lancet Neurol. 7, 400-408. doi: 10.1016/S1474-4422(08)70065-6

Meissner, W., Prunier, C., Guilloteau, D., Chalon, S., Gross, C. E., and Bezard, E. (2003). Time-course of nigrostriatal degeneration in a progressive MPTPlesioned macaque model of Parkinson's disease. Mol. Neurobiol. 28, 209-218. doi: 10.1385/MN:28:3:209

Nemani, V. M., Lu, W., Berge, V., Nakamura, K., Onoa, B., Lee, M. K., et al. (2010). Increased expression of $\alpha$-synuclein reduces neurotransmitter release by inhibiting synaptic vesicle reclustering after endocytosis. Neuron $65,66-79$. doi: 10.1016/j.neuron.2009.12.023

Nguyen, J. B., Sanchez-Pernaute, R., Cunningham, J., and Bankiewicz, K. S. (2001). Convection-enhanced delivery of AAV-2 combined with heparin increases TK gene transfer in the rat brain. Neuroreport 12, 1961-1964. doi: 10.1097/00001756-200107030-00037

Nirenberg, M. J., Vaughan, R. A., Uhl, G. R., Kuhar, M. J., and Pickel, V. M. (1996). The dopamine transporter is localized to dendritic and axonal plasma membranes of nigrostriatal dopaminergic neurons. J. Neurosci. 16, 436-447.

Nutt, J. G., Burchiel, K. J., Comella, C. L., Jankovic, J., Lang, A. E., Laws, E. R. Jr., et al. (2003). Randomized, double-blind trial of glial cell line-derived neurotrophic factor (GDNF) in PD. Neurology 60, 69-73. doi: 10.1212/WNL.60.1.69 
Paratcha, G., and Ledda, F. (2008). GDNF and GFR $\alpha$ : a versatile molecular complex for developing neurons. Trends Neurosci. 31, 384-391. doi: 10.1016/j.tins.2008.05.003

Peelaerts, W., Bousset, L., Van der Perren, A., Moskalyuk, A., Pulizzi, R., Giugliano, M., et al. (2015). $\alpha$-Synuclein strains cause distinct synucleinopathies after local and systemic administration. Nature 522, 340-344. doi: 10.1038/nature14547

Pertusa, M., Garcia-Matas, S., Mammeri, H., Adell, A., Rodrigo, T., Mallet, J., et al. (2008). Expression of GDNF transgene in astrocytes improves cognitive deficits in aged rats. Neurobiol. Aging 29, 1366-1379. doi: 10.1016/j.neurobiolaging.2007.02.026

Quartu, M., Serra, M. P., Boi, M., Ferretti, M. T., Lai, M. L., and Del Fiacco, M. (2007). Tissue distribution of Ret, GFRalpha-1, GFRalpha-2 and GFRalpha-3 receptors in the human brainstem at fetal, neonatal and adult age. Brain Res. 1173, 36-52. doi: 10.1016/j.brainres.2007.07.064

Ramaswamy, S., McBride, J. L., Herzog, C. D., Brandon, E., Gasmi, M., Bartus, R. T., et al. (2007). Neurturin gene therapy improves motor function and prevents death of striatal neurons in a 3-nitropropionic acid rat model of Huntington's disease. Neurobiol. Dis. 26, 375-384. doi: 10.1016/j.nbd.2007.01.003

Ramsey, A. J., and Fitzpatrick, P. F. (1998). Effects of phosphorylation of serine 40 of tyrosine hydroxylase on binding of catecholamines: evidence for a novel regulatory mechanism. Biochemistry 37, 8980-8986. doi: 10.1021/bi9805821

Rosenblad, C., Georgievska, B., and Kirik, D. (2003). Long-term striatal overexpression of GDNF selectively downregulates tyrosine hydroxylase in the intact nigrostriatal dopamine system. Eur. J. Neurosci. 17, 260-270. doi: 10.1046/j.1460-9568.2003.02456.x

Runeberg-Roos, P., Piccinini, E., Penttinen, A. M., Matlik, K., Heikkinen, H., Kuure, S., et al. (2016). Developing therapeutically more efficient Neurturin variants for treatment of Parkinson's disease. Neurobiol. Dis. 96, 335-345. doi: 10.1016/j.nbd.2016.07.008

Sajadi, A., Bauer, M., Thony, B., and Aebischer, P. (2005). Long-term glial cell line-derived neurotrophic factor overexpression in the intact nigrostriatal system in rats leads to a decrease of dopamine and increase of tetrahydrobiopterin production. J. Neurochem. 93, 1482-1486. doi: 10.1111/j.1471-4159.2005.03139.x

Saklayen, S. S., Mabrouk, O. S., and Pehek, E. A. (2004). Negative feedback regulation of nigrostriatal dopamine release: mediation by striatal $\mathrm{D} 1$ receptors. J. Pharmacol. Exp. Ther. 311, 342-348. doi: 10.1124/jpet.104.067991

Salvatore, M. F., Zhang, J. L., Large, D. M., Wilson, P. E., Gash, C. R., Thomas, T. C., et al. (2004). Striatal GDNF administration increases tyrosine hydroxylase phosphorylation in the rat striatum and substantia nigra. J. Neurochem. 90, 245-254. doi: 10.1111/j.1471-4159.2004.02496.x

Sariola, H., and Saarma, M. (2003). Novel functions and signalling pathways for GDNF. J. Cell Sci. 116, 3855-3862. doi: 10.1242/jcs.00786

Sauer, H., and Oertel, W. H. (1994). Progressive degeneration of nigrostriatal dopamine neurons following intrastriatal terminal lesions with 6hydroxydopamine: a combined retrograde tracing and immunocytochemical study in the rat. Neuroscience 59, 401-415. doi: 10.1016/0306-4522(94)90605-X

Schulz-Schaeffer, W. J. (2015). Is cell death primary or secondary in the pathophysiology of idiopathic Parkinson's Disease? Biomolecules 5, 1467-1479. doi: 10.3390/biom5031467

Shehadeh, L., Mitsi, G., Adi, N., Bishopric, N., and Papapetropoulos, S. (2009). Expression of Lewy body protein septin 4 in postmortem brain of Parkinson's disease and control subjects. Mov. Disord. 24, 204-210. doi: 10.1002/mds.22306

Su, X., Kells, A. P., Huang, E. J., Lee, H. S., Hadaczek, P., Beyer, J., et al. (2009). Safety evaluation of AAV2-GDNF gene transfer into the dopaminergic nigrostriatal pathway in aged and parkinsonian rhesus monkeys. Hum. Gene Ther. 20, 1627-1640. doi: 10.1089/hum.2009.103

Tardieu, M., Zerah, M., Husson, B., de Bournonville, S., Deiva, K., Adamsbaum, C., et al. (2014). Intracerebral administration of adeno-associated viral vector serotype rh.10 carrying human SGSH and SUMF1 cDNAs in children with mucopolysaccharidosis type IIIA disease: results of a phase I/II trial. Hum. Gene Ther. 25, 506-516. doi: 10.1089/hum.2013.238

Tereshchenko, J., Maddalena, A., Bahr, M., and Kugler, S. (2014). Pharmacologically controlled, discontinuous GDNF gene therapy restores motor function in a rat model of Parkinson's disease. Neurobiol. Dis. 65, 35-42. doi: 10.1016/j.nbd.2014.01.009

Tomac, A., Lindqvist, E., Lin, L. F., Ogren, S. O., Young, D., Hoffer, B. J., et al. (1995). Protection and repair of the nigrostriatal dopaminergic system by GDNF in vivo. Nature 373, 335-339. doi: 10.1038/373335a0
Tong, J., Wong, H., Guttman, M., Ang, L. C., Forno, L. S., Shimadzu, M., et al. (2010). Brain alpha-synuclein accumulation in multiple system atrophy, Parkinson's disease and progressive supranuclear palsy: a comparative investigation. Brain 133, 172-188. doi: 10.1093/brain/awp282

Tsui, C. C., and Pierchala, B. A. (2010). The differential axonal degradation of Ret accounts for cell-type-specific function of glial cell line-derived neurotrophic factor as a retrograde survival factor. J. Neurosci. 30, 5149-5158. doi: 10.1523/JNEUROSCI.5246-09.2010

Uhl, G. R. (2003). Dopamine transporter: basic science and human variation of a key molecule for dopaminergic function, locomotion, and parkinsonism. Mov. Disord. 18(Suppl. 7), S71-S80. doi: 10.1002/mds. 10578

Van der Perren, A., Toelen, J., Casteels, C., Macchi, F., Van Rompuy, A. S., Sarre, S., et al. (2015). Longitudinal follow-up and characterization of a robust rat model for Parkinson's disease based on overexpression of alphasynuclein with adeno-associated viral vectors. Neurobiol. Aging 36, 1543-1558. doi: 10.1016/j.neurobiolaging.2014.11.015

Volpicelli-Daley, L. A., Gamble, K. L., Schultheiss, C. E., Riddle, D. M., West, A. B., and Lee, V. M. (2014). Formation of $\alpha$-synuclein Lewy neurite-like aggregates in axons impedes the transport of distinct endosomes. Mol. Biol. Cell 25, 4010-4023. doi: 10.1091/mbc.E14-02-0741

Volpicelli-Daley, L. A., Kirik, D., Stoyka, L. E., Standaert, D. G., and Harms, A. S. (2016). How can rAAV- $\alpha$-synuclein and the fibril $\alpha$-synuclein models advance our understanding of Parkinson's disease? J. Neurochem. 139(Suppl. 1), 131-155. doi: 10.1111/jnc. 13627

Walker, D. G., Beach, T. G., Xu, R., Lile, J., Beck, K. D., McGeer, E. G., et al. (1998). Expression of the proto-oncogene Ret, a component of the GDNF receptor complex, persists in human substantia nigra neurons in Parkinson's disease. Brain Res. 792, 207-217. doi: 10.1016/S0006-8993(98)00131-0

Wang, L., Muramatsu, S., Lu, Y., Ikeguchi, K., Fujimoto, K., Okada, T., et al. (2002). Delayed delivery of AAV-GDNF prevents nigral neurodegeneration and promotes functional recovery in a rat model of Parkinson's disease. Gene Ther. 9, 381-389. doi: 10.1038/sj.gt.3301682

Warren Olanow, C., Bartus, R. T., Baumann, T. L., Factor, S., Boulis, N., Stacy, M., et al. (2015). Gene delivery of neurturin to putamen and substantia nigra in Parkinson disease: a double-blind, randomized, controlled trial. Ann. Neurol. 78, 248-257. doi: 10.1002/ana.24436

Watson, F. L., Heerssen, H. M., Moheban, D. B., Lin, M. Z., Sauvageot, C. M. Bhattacharyya, A., et al. (1999). Rapid nuclear responses to target-derived neurotrophins require retrograde transport of ligand-receptor complex. $J$. Neurosci. 19, 7889-7900.

Westerink, B. H., de Boer, P., Santiago, M., and De Vries, J. B. (1994). Do nerve terminals and cell bodies of nigrostriatal dopaminergic neurons of the rat contain similar receptors? Neurosci. Lett. 167, 109-112.

Yang, F., Feng, L., Zheng, F., Johnson, S. W., Du, J., Shen, L., et al. (2001). GDNF acutely modulates excitability and A-type $\mathrm{K}^{+}$channels in midbrain dopaminergic neurons. Nat. Neurosci. 4, 1071-1078. doi: 10.1038/nn734

Yang, X., Mertens, B., Lehtonen, E., Vercammen, L., Bockstael, O., Chtarto, A., et al. (2009). Reversible neurochemical changes mediated by delayed intrastriatal glial cell line-derived neurotrophic factor gene delivery in a partial Parkinson's disease rat model. J. Gene Med. 11, 899-912. doi: 10.1002/jgm.1377

Zheng, J. S., Tang, L. L., Zheng, S. S., Zhan, R. Y., Zhou, Y. Q., Goudreau, J., et al. (2005). Delayed gene therapy of glial cell line-derived neurotrophic factor is efficacious in a rat model of Parkinson's disease. Brain Res. Mol. Brain Res. 134, 155-161. doi: 10.1016/j.molbrainres.2004.06.029

Zhu, S., Zhao, C., Wu, Y., Yang, Q., Shao, A., Wang, T., et al. (2015). Identification of a Vav2-dependent mechanism for GDNF/Ret control of mesolimbic DAT trafficking. Nat. Neurosci. 18, 1084-1093. doi: 10.1038/nn.4060

Conflict of Interest Statement: The authors declare that the research was conducted in the absence of any commercial or financial relationships that could be construed as a potential conflict of interest.

Copyright (๑) 2017 Tenenbaum and Humbert-Claude. This is an open-access article distributed under the terms of the Creative Commons Attribution License (CC BY). The use, distribution or reproduction in other forums is permitted, provided the original author(s) or licensor are credited and that the original publication in this journal is cited, in accordance with accepted academic practice. No use, distribution or reproduction is permitted which does not comply with these terms. 